\title{
Identification and recombinant expression of an antimicrobial peptide (cecropin B-like) from soybean pest Anticarsia gemmatalis
}

\author{
Luís Felipe Costa Ramos', João Henrique de Oliveira Rangel1', Guilherme Caldas Andrade', Carolina Lixa', \\ Livia Vieira Araujo de Castilho,2, Fábio César Sousa Nogueira', Anderson S. Pinheiro1, Fabio Mendonça Gomes ${ }^{3}$, \\ Cristiane Dinis AnoBom¹, Rodrigo Volcan Almeida ${ }^{1}$ (D), Danielle Maria Perpétua de Oliveira ${ }^{1 *}$ (D) \\ ${ }^{1}$ Department of Biochemistry, Institute of Chemistry, Center of Mathematical and Natural Sciences, Federal University of Rio de Janeiro (UFRJ), \\ Rio de Janeiro, RJ, Brazil. \\ ${ }^{2}$ Alberto Luiz Coimbra Institute of Graduate Studies and Research (COPPE), Federal University of Rio de Janeiro (UFRJ), Rio de Janeiro, RJ, Brazil. \\ ${ }^{3}$ Carlos Chagas Filho Institute of Biophysics, Federal University of Rio de Janeiro (UFRJ), Rio de Janeiro, RJ, Brazil.
}

\section{Keywords:}

Antimicrobial peptides

Cecropin B

Heterologous expression

Anticarsia gemmatalis

Agricultural pest

\begin{abstract}
Background: Insects can be found in numerous diverse environments, being exposed to pathogenic organisms like fungi and bacteria. Once these pathogens cross insect physical barriers, the innate immune system operates through cellular and humoral responses. Antimicrobial peptides are small molecules produced by immune signaling cascades that develop an important and generalist role in insect defenses against a variety of microorganisms. In the present work, a cecropin B-like peptide (AgCecropB) sequence was identified in the velvetbean caterpillar Anticarsia gemmatalis and cloned in a bacterial plasmid vector for further heterologous expression and antimicrobial tests. Methods: AgCecropB sequence (without the signal peptide) was cloned in the plasmid vector pET-M30-MBP and expressed in the Escherichia coli BL21(DE3) expression host. Expression was induced with IPTG and a recombinant peptide was purified using two affinity chromatography steps with Histrap column. The purified peptide was submitted to high-resolution mass spectrometry (HRMS) and structural analyses. Antimicrobial tests were performed using gram-positive (Bacillus thuringiensis) and gram-negative (Burkholderia kururiensis and E. coli) bacteria.

Results: AgCecropB was expressed in E. coli BL21 (DE3) at $28^{\circ} \mathrm{C}$ with IPTG $0.5 \mathrm{mM}$. The recombinant peptide was purified and enriched after purification steps. HRMS confirmed AgCrecropB molecular mass $(4.6 \mathrm{kDa})$ and circular dichroism assay showed $a$-helix structure in the presence of SDS. AgCrecropB inhibited almost 50\% of grampositive B. thuringiensis bacteria growth.

Conclusions: The first cecropin B-like peptide was described in A. gemmatalis and a recombinant peptide was expressed using a bacterial platform. Data confirmed tertiary structure as predicted for the cecropin peptide family. AgCecropB was capable to inhibit B. thuringiensis growth in vitro.
\end{abstract}

* Correspondence: danioliveira@iq.ufrj.br https://doi.org/10.1590/1678-9199-JVATITD-2020-0127

Received: 24 August 2020; Accepted: 11 January 2021; Published online: 12 March 2021 


\section{Background}

Insects are one of the largest and most diverse groups of animals, representing about 80 to $90 \%$ of the animal biodiversity [1]. As in other animals, insects must cope with immune challenges from parasites and other pathogens during their life cycle [2]. The digestive tract of insects is the first physical and immune barrier against invading microorganisms that are ingested with food [3]. When this barrier is broken, invading microorganisms are exposed to a variety of cellular and humoral processes that support the host defense [4]. In that regard, the production of antimicrobial peptides (AMPs) is one of the key responses in the humoral immune system [5].

AMPs are cationic peptides usually ranging from 20 to 50 amino acid residues [6] that exhibit broad activity against bacteria, fungi, as well as certain parasites and viruses [7-9]. In insects, these peptides are mainly synthesized in the fat body $[10,11]$, hemocytes, and digestive tract [12]. Cecropins are a well-studied class of antimicrobial peptides, with an a helical structure, first described in Hyalophora cecropia hemolymph $[13,14]$ and later described in other lepidopterans and dipterans [15-18]. They belong to a large family of cationic AMPs, which is structured the $a$-helicoidal secondary structure when they encounter microorganism surfaces [19]. These peptides have shown antimicrobial activity against a wide spectrum of bacteria [20-23] and fungi [24].

The soybean caterpillar Anticarsia gemmatalis Hübner (Lepidoptera: Noctuidae) is the main soybean defoliating pest in Brazil [25] and is found from the United States to Argentina [26]. At present, A. gemmatalis biological control in soybean fields is mostly done by A. gemmatalis nucleopolyhedrovirus (AgMNPV) and Bacillus thuringiensis. However, studies have shown that $A$. gemmatalis can develop resistance to these agents [27, 28]. In this study, we identified a cecropin B-like peptide from the soybean caterpillar A. gemmatalis. We expressed and characterized the mature peptide in vitro, and analyzed its activity against three species of bacteria. This peptide is probably produced by the humoral immune system after bacterial challenge and it could be related to resistance mechanisms to biological control with pathogens.

\section{Methods}

\section{Insects}

The A. gemmatalis colony was maintained as previously described [29]. Briefly, Larvae were reared on artificial diet and maintained under $25 \pm 3^{\circ} \mathrm{C}, 70 \pm 10 \%$ relative humidity, and $14: 10 \mathrm{~h}$ (light/ dark) photoperiod and collected at the $5^{\text {th }}$ instar for manipulation.

\section{Bacterial strains}

Four bacterial strains were used in this work. Escherichia coli DH5a was used for plasmid propagation, while E. coli BL21 (DE3) was used for heterologous expression. They were kindly provided by Dr. Bianca C. Neves (Institute of Chemistry, UFRJ,
Brazil). Bacillus thuringiensis kurstaki strain LFB-FIOCRUZ 475, provided by Dr. Leon Rabinovitch (CCGB/IOC/FIOCRUZ, Brazil), and Burkholderia kururiensis strain, provided by Dr. Bianca C. Neves (Institute of Chemistry, UFRJ, Brazil) were used in the antimicrobial tests together with the E. coli DH5a strain.

\section{Sequence analysis by bioinformatics}

The entire sequence of cecropin B-like peptide was identified through BLASTX alignment search tool (https://blast.ncbi.nlm. nih.gov/Blast.cgi) against an A. gemmatalis midgut transcriptome analysis (this query sequence was deposited in the GenBank database, code MW330381). A multiple sequence alignment using PRALINE (Center for Integrative Bioinformatics VU) (http://www.ibi.vu.nl/programs/pralinewww) was performed to identify possible conserved regions [30]. The SignalP 4.1 Server program (Department of Bio and Health Informatics) (http://www.cbs.dtu.dk/services/SignalP) [31] was used to map the possible cleavage region. The amino acid sequence of the mature peptide was named AgCecropB. Physico-chemical parameters of the AgCecropB sequence, such as theoretical pI and the expected mass, were determined in ExPASy ProtParam (https://web.expasy.org/protparam/). Phyre2 (Protein Homology / analogY recognition Engine V 2.0) (http://www.sbg.bio.ic.ac.uk/ phyre2/html/page.cgi?id=index) was used to search for structural alignments to generate a structural model for AgCecropB. The suggested template was papiliocin c2la2A. All structure comparisons were performed in PyMOL 4.0 (Schrödinger) (https://pymol.org/2/).

\section{RNA extraction and cloning of AgCecropB}

RNA extracts were prepared using pools of eight $5^{\text {th }}$ instar larvae. Specimens were dissected and midgut epithelia were cleaned and used for total RNA extraction with Trizol ${ }^{\circledR}$ (Invitrogen) [32]. Total RNA was quantified using a Qubit ${ }^{\circledR} 2.0$ Fluorometer (Invitrogen), following the manufacturer's recommendations. The RNA samples were analyzed by electrophoresis and used to produce cDNA using the SuperScript III First-Strand Kit (Invitrogen) following the manufacturer's recommendations.

Cloning was performed as previously described [33], with minor modifications. The DNA sequence of AgCecropB was amplified by PCR. The oligonucleotides were designed and analyzed by using the OligoAnalyzer Tool, from Integrated DNA Technologies ${ }^{\mathrm{TM}}$ (https://www.idtdna.com/pages). Forward primer (5'- TTC CAT GGC GCC CGA GCC TAG GTG G -3') and reverse primer (5'- GCG $\underline{\text { CTC GAG }}$ TTA TTT TCC TAA GGC TTT TGC -3') had NcoI and XhoI restriction site sequences respectively inserted (underlined), complementary AgCecropB sequence regions for primers alignment (bold) and a stop codon sequence was inserted before $X h o I$ restriction site sequence (in italic). The template amplification was performed under Platinum Taq standard conditions with $57^{\circ} \mathrm{C}$ for annealing temperature. NcoI (New England Biolabs, USA) and XhoI (New England Biolabs, USA) restriction enzymes were used for both amplicon 
and plasmid digestions. The bacterial expression plasmid pETM30-MBP which encodes an N-terminal 6XHis tag, followed by maltose-binding protein $(\mathrm{MBP})(42.5 \mathrm{kDa})$ and a TEV protease cleavage site (ENLYFQG), was used to clone AgCecropB [34]. Competent $E$. coli BL21 (DE3) cells were transformed with the ligation mixture and selected for antibiotic-resistant colonies on Luria Bertani (LB) agar containing $100 \mu \mathrm{g} / \mathrm{mL}$ kanamycin.

\section{Heterologous protein expression}

A single colony from freshly transformed bacteria was inoculated in $4 \mathrm{~mL}$ of Luria Bertani (LB) broth containing $100 \mu \mathrm{g} / \mathrm{mL}$ kanamycin and cultured for $18 \mathrm{~h}$ at $37^{\circ} \mathrm{C}, 200 \mathrm{rpm}$ in an orbital shaker. The culture was transferred to $25 \mathrm{~mL}$ of fresh LB broth containing $100 \mu \mathrm{g} / \mathrm{mL}$ kanamycin and grown at $37^{\circ} \mathrm{C}, 200$ rpm until the optical density at $600 \mathrm{~nm}$ (O.D.600) reached 0.6. Subsequently, heterologous expression was induced by $0.5 \mathrm{mM}$ isopropyl- $\beta$-D-thiogalactopyranoside (IPTG) (Sigma, USA). Bacterial cells were allowed to grow for $16 \mathrm{~h}$ at $28^{\circ} \mathrm{C}$ at $200 \mathrm{rpm}$ and $1 \mathrm{~mL}$ aliquots were collected at different time intervals to follow recombinant protein expression. These aliquots were centrifuged at $8000 \mathrm{xg}$ for $10 \mathrm{~min}$ at $4{ }^{\circ} \mathrm{C}$. The culture precipitates were boiled for $20 \mathrm{~min}$ in sample loading buffer $[1.7 \mathrm{mM}$ Tris- $\mathrm{HCl}$ (pH 7.6), $0.005 \%$ bromophenol blue, $0.005 \%$ xylene cyanol FF, $10 \%$ glycerol, $10 \mathrm{mM}$ ethylenediaminetetraacetic acid (EDTA), $10 \mathrm{mM} \mathrm{b}$-mercaptoethanol and protein content was analyzed by $12 \%$ SDS PAGE according Laemmli [35] and stained with Coomassie Brilliant Blue [36]. For large scale expression, the 18 $\mathrm{h}$ inoculum was transferred to fresh LB broth $(1 \mathrm{~L})$ containing $100 \mu \mathrm{g} / \mathrm{mL}$ kanamycin and grown at $37^{\circ} \mathrm{C}$ and $200 \mathrm{rpm}$ until O.D.600 reached 0.6. Hisx6MBP-AgCecropB (recombinant protein) expression was induced with $0.5 \mathrm{mM} \mathrm{IPTG}$ and grown for an additional $3 \mathrm{~h}$ at $28^{\circ} \mathrm{C}, 200 \mathrm{rpm}$. After that, the culture was harvested by centrifugation at $8000 \mathrm{xg}$ for $30 \mathrm{~min}$ at $4{ }^{\circ} \mathrm{C}$. Culture precipitate was suspended in $50 \mathrm{mM}$ sodium phosphate buffer, $0.5 \mathrm{M} \mathrm{NaCl}$ (pH 7.0) (This solution is named as buffer A in all work) containing protease inhibitor cocktail SIGMAFAST ${ }^{\mathrm{TM}}$ Protease Inhibitor Cocktail Tablets, EDTA Free (Sigma-Aldrich) and disrupted by sonication (30s on, 59s off; 15 cycles). The mixture was centrifuged in $8.000 \mathrm{xg} 4^{\circ} \mathrm{C}$ for $30 \mathrm{~min}$ and samples were submitted to $12 \%$ SDS-PAGE analysis. The soluble fraction was submitted to purification.

\section{Purification of AgCecropB}

Recombinant AgCecropB was purified by two $\mathrm{Ni}^{2+}$-affinity chromatography steps using a 5-mL HisTrap HP (GE Healthcare) column attached to an ÄktaPrime Plus purification system (GE Healthcare). The supernatant fraction was injected onto the column, previously equilibrated with buffer A (as described before), and the recombinant protein was eluted using an imidazole gradient with buffer B [50 mM sodium phosphate (pH 7.0), 0.5M NaCl, $1 \mathrm{M}$ imidazole]. Fractions containing Hisx6MBP-AgCecropB were identified and submitted to dialysis to remove imidazole. The Hisx6MBP tag was removed by proteolysis using an in-house produced His6-TEV at 5:1 ratio (w/w protein:TEV) during $96 \mathrm{~h}$ at $4{ }^{\circ} \mathrm{C}$. After cleavage, a second $\mathrm{Ni}^{2+}$-affinity purification step was performed to remove His6-TEV protease and Hisx6MBP from AgCecropB. This step was performed in the same conditions described above and analyzed by $18 \%$ SDS-PAGE. The recombinant peptide was collected directly in the wash step. AgCecropB concentration was determined using Qubit $^{\circledR}$ 2.0 Fluorometer (Invitrogen) following the manufacturer's instructions.

\section{High resolution mass spectrometry (HRMS) of AgCecropB}

Sample containing AgCecropB was vacuum dried and solubilized in $50 \%$ acetonitrile and $10 \%$ ammonium acetate and analyzed by direct infusion on the LTQ Orbitrap Velos mass spectrometer (Thermo Scientific). The mass spectrometer was equipped with a nano-electrospray ionization source (n-ESI) and the sample was infused through nano capillaries (PicoTip Emitter, Glass Tip, coating 1P-4P, New Objective). The source parameters were ionization voltage of $2 \mathrm{kV}$ and temperature $200{ }^{\circ} \mathrm{C}$. The acquisition consisted of a complete scan of the ions in high resolution on the Orbitrap analyzer, with a resolution of 60,000 (for $\mathrm{m} / \mathrm{z} 400$ ), and a range of $\mathrm{m} / \mathrm{z}$ 400-2000. The acquired spectra were evaluated using the Xcalibur 2.1 software (Thermo Scientific).

\section{AgCecropB structural analysis}

The circular dichroism (CD) spectroscopy and intrinsic fluorescence spectroscopy were performed as previously described [37]. For CD assay, spectra were obtained in a Jasco J-715 1505 model spectropolarimeter (Jasco Corp.), using quartz cuvette $0.1 \mathrm{~cm}$, and analyzed in the region of 190 to $260 \mathrm{~nm}$. AgCecropB spectra were obtained as an average of eight reads in $100 \mathrm{~nm} / \mathrm{min}$ velocity. Experiments were conducted with the anionic detergent sodium dodecyl sulfate (SDS) (Sigma Aldrich ${ }^{\circ}$. The peptide was incubated at different SDS concentrations (50 and $100 \mu \mathrm{M}$ ) for $16 \mathrm{~h}$ at room temperature. Baselines (only buffers were used) were subtracted from the peptide spectra. The mean residue molar ellipticity at $222 \mathrm{~nm},[\theta] 222$, was plotted in function of SDS concentration. To tryptophan intrinsic fluorescence spectroscopy, assays were acquired in a fluorimeter Cary Eclipse (Varian Inc.). Samples were excited to $280 \mathrm{~nm}$ and fluorescence emission of 300 to $420 \mathrm{~nm}$ was analyzed. Data of AgCecropB was taken at room temperature in the same concentrations of SDS used in CD assays, with $1 \mu \mathrm{M}$ concentration of protein.

\section{Antimicrobial tests}

Stock cultures of B. thuringiensis, E. coli (DH5a), and B. kururiensis were plated in nutrient agar medium (HiMedia Laboratories) and incubated for $16 \mathrm{~h}$ at $37^{\circ} \mathrm{C}$. One colony from each plate was inoculated in $3 \mathrm{~mL}$ of nutrient broth medium (HiMedia Laboratories) and grown for $16 \mathrm{~h}$ at $37^{\circ} \mathrm{C}, 200 \mathrm{rpm}$. A $250 \mu \mathrm{L}$ aliquot was inoculated in nutrient broth $(25 \mathrm{~mL})$ and 
cultures were grown for $6 \mathrm{~h}$ at $37^{\circ} \mathrm{C}, 200 \mathrm{rpm}$ to ensure that the exponential phase of growth was reached. O.D.600 was measured and cultures were diluted in ultrapure $\mathrm{H}_{2} \mathrm{O}$ to 0.4 (O.D.600) for antimicrobial tests.

Assays were carried out in 96-well sterile plates as follows: 100 $\mu \mathrm{L}$ of nutrient broth medium, $50 \mu \mathrm{L}$ of bacterial growth (final O.D.600 = 0.1), and $50 \mu \mathrm{L}$ of AgCecropB solubilized in buffer A were added to each well ( $9 \mu \mathrm{M}$ AgCecropB in the assay). As a negative control of growth inhibition, $50 \mu \mathrm{L}$ of buffer was used. Control by using $26.3 \mu \mathrm{M}$ chloramphenicol was tested. Plates were incubated by 20 hours at $37^{\circ} \mathrm{C}$ and read at $600 \mathrm{~nm}$ in a Spectra Max M2 plate reader (Molecular Devices). Tests were performed in quintuplicates and all statistical analyses were done in GraphPad 7 Prism.

\section{Results}

\section{Bioinformatic analysis of AgCecropB}

The primary sequence of the antimicrobial peptide was identified in an A. gemmatalis midgut transcriptome analysis (Figure 1A). This peptide (AgCecropB) has a total of 63 amino acids, with major number of conserved amino acids between positions 31 and 54, which belongs to the mature peptide as observed after PRALINE alignment using other cecropins sequences from Lepidoptera and Diptera order representatives (Figure 2A). Using the Signal P 4.1, a cleavage site region was identified between amino acid positions 22 and 23 (two alanine residues) of the complete peptide sequence (data not shown). The theoretical size of the recombinant peptide $(4,656.61 \mathrm{Da})$ and the theoretical pI (10.71) were obtained by ExPASy Tools analysis.

Papiliocin, an antimicrobial peptide that belongs to the cecropin family first described in Papilio xuthus [38] was chosen by Phyre $^{2}$ as the best template for the modeling of AgCecropB (reference c2la2A). Comparing the suggested structure with AgceCropB, we observed a 90\% structure similarity, which showed two $\alpha$-helixes linked by a hinge, generally formed by a glycine and proline amino acids (Figure 2B).

\section{Cloning and heterologous expression of AgCecropB}

We designed specific primers for mature peptide amplification. Alanine/methionine residues were added to the recombinant peptide sequence AgCecropB, due to the cleavage site NcoI, and a glycine residue remains due to TEV cleavage site (Figure 1B). The partial sequence of $\mathrm{AgCecropB}$ was amplified from midgut cDNA pools. The fragment was cloned into a pETM30-MBP plasmid and the sequence was confirmed by colony PCR and sequencing. This cloned sequence was deposited in the GenBank database, code MW310628 and it contains the cloned sequence and predicted protein sequence. E. coli BL21 (DE3) cells were transformed for heterologous expression [39] and a protein with the predicted mass $(48.5 \mathrm{kDa})$ of Hisx6MBP-AgCecropB was expressed. Optimal conditions were determined as a $3 \mathrm{~h}$ induction time using IPTG $0.5 \mathrm{mM}$ (final concentration), at $28^{\circ} \mathrm{C}$ (Figure $3 \mathrm{~A}$ ). Following the lysis step, we observed that a large fraction of Hisx6MBP-AgCecropB was found on the soluble fraction (Figure 3B).

\section{A atgaattcctcacgagtattgttcttcgtgttcgcttgttttgtagctttggcgacagtg \begin{tabular}{cccccccccccccccccccc}
$M$ & $N$ & $F$ & $S$ & $R$ & $V$ & $L$ & $F$ & $F$ & $V$ & $F$ & $A$ & $C$ & $F$ & $V$ & $A$ & $L$ & $A$ & $T$ & $V$ \\
\hline tcggcggogccogagcctaggtggaaggtcttcaagaaaattgagaaggtcggtcgcaat
\end{tabular} $\begin{array}{llllllllllllllllllll}\mathrm{S} & \mathrm{A} & \boldsymbol{A} & \boldsymbol{P} & \boldsymbol{E} & \boldsymbol{P} & \mathrm{R} & \mathrm{W} & \mathrm{K} & \mathrm{V} & \boldsymbol{F} & \mathrm{K} & \mathrm{K} & \mathrm{I} & \mathbf{E} & \mathrm{K} & \mathrm{V} & \mathbf{G} & \mathrm{R} & \mathrm{N}\end{array}$ $\overline{\text { gtccgcgatggtatcatcaaagctggtccagccatcggagtcctgggacaagcaaaagcc }}$ $\begin{array}{lllllllllllllllllllll}V & R & D & G & I & I & K & A & G & P & A & I & G & V & I & G & Q & A & K & A\end{array}$ ttaggaaaataa L $\quad$ G K *}

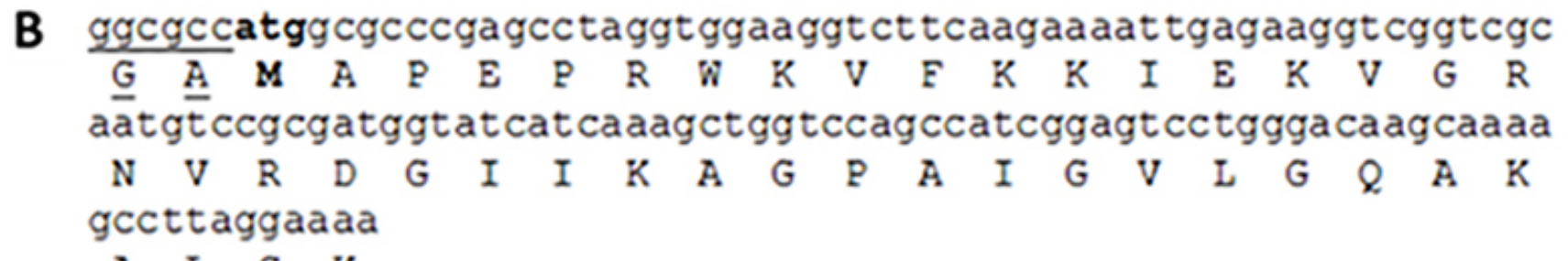

Figure 1. (A) Cecropin B-like peptide sequence identified in A. gemmatalis midgut transcriptome. Signal peptide sequence (underlined in red) was detected using SignalP software. Underlined nucleotides were used for primer design. Pro region peptide is in italic. (B) Recombinant cecropin B-like (AgCecropB) sequence, with remaining residues from TEV cleavage site (underlined in black) and Ncol restriction site (bold). 


\section{A Unconserved 012345678910 Conserved}

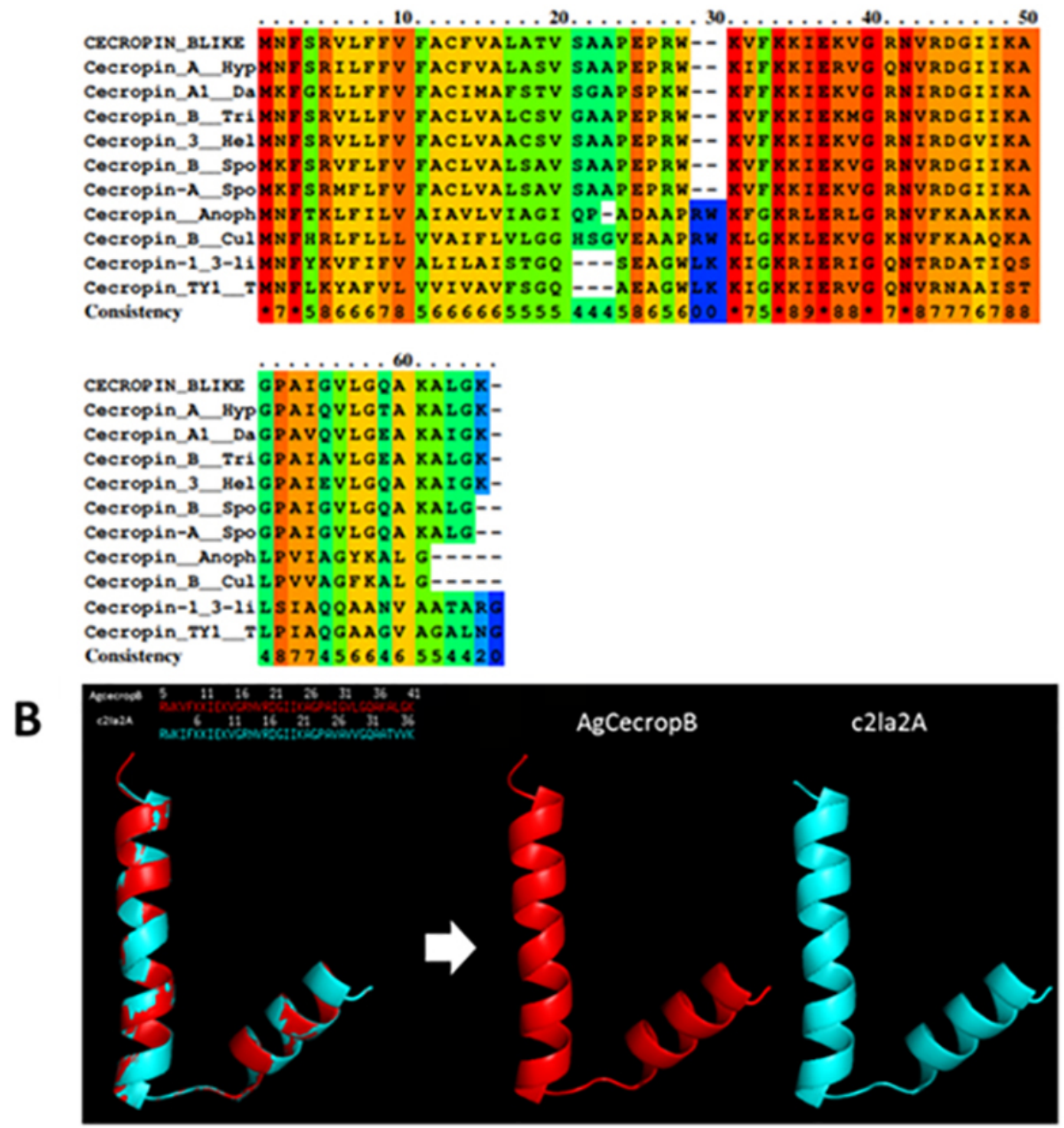

Figure 2. AgCecropB pre-pro-peptide primary sequence alignment and tertiary structure modeling. (A) PRALINE alignment result using AgCecropB pre-propeptide sequence identified in transcriptome and other lepidoptera and diptera cecropins sequences deposited in GenBank. CECROPIN_BLIKE: Cecropin B prepro-peptide from A. gemmatalis transcriptome (GenBank database code MW330381); Cecropin_A_Hyp: Cecropin A from Hyphantria cunea; Cecropin_A1_Da: Cecropin A1 from Danaus plexippus plexippus; Cecropin_B_Tri: Cecropin B from Trichoplusia ni; Cecropin_3_Hel: Helicoverpa armigera Cecropin 3; Cecropin_B_ Spo: Cecropin B from Spodoptera exigua; Cecropin-A_Spo: Cecropin A from Spodoptera litura; Cecropin_Anoph: Anopheles darling cecropin; Cecropin_B_Cul: Cecropin B from Culex quinquefasciatus; Cecropin-1_3-li: Drosophila hydei 1/3-like cecropin; Cecropin_TY1_T: Tabanus yao cecropin 1. (B) Overlapping of the tertiary structure models of cecropin B-like peptide and papiliocin c2la2A. Papiliocin c21a2A isolated from Papilio xuthus was the suggested template by Phyre2 for $\mathrm{AgCecropB}$ tertiary structure modeling. PyMOL generated the overlapping model based on both peptides mature sequence.

\section{AgCecropB purification}

Chromatogram of first Histrap $\mathrm{Ni}^{2+}$ affinity purification was analyzed, and two peaks were observed (Figure 4A). The recombinant protein was eluted on peak 2 (P2) at $160 \mathrm{mM}$ imidazole concentration. This sample was harvested and the Hisx6MBP tag was cleaved by TEV endoprotease (Fig 4B). The resulting sample was submitted to a new step of affinity chromatography to purify recombinant $\mathrm{AgCecropB}$ from Hisx6MBP tag and TEV endoprotease (Figure 5A). One peak containing AgCecropB recombinant peptide was detected during the washing column step before the imidazole gradient (Figure 5B).

\section{AgCecropB HRMS and structural assays}

HRMS of recombinant AgCecropB was prepared and the full scan analysis revealed three major peaks: $\mathrm{m} / \mathrm{z} 776.9592(\mathrm{z}=$ 6), $932.1492(\mathrm{z}=5)$, and $1164.9347(\mathrm{z}=4)$ (Figure 6A). The obtained average mass is approximately $4,656 \mathrm{Da}$, confirming the 

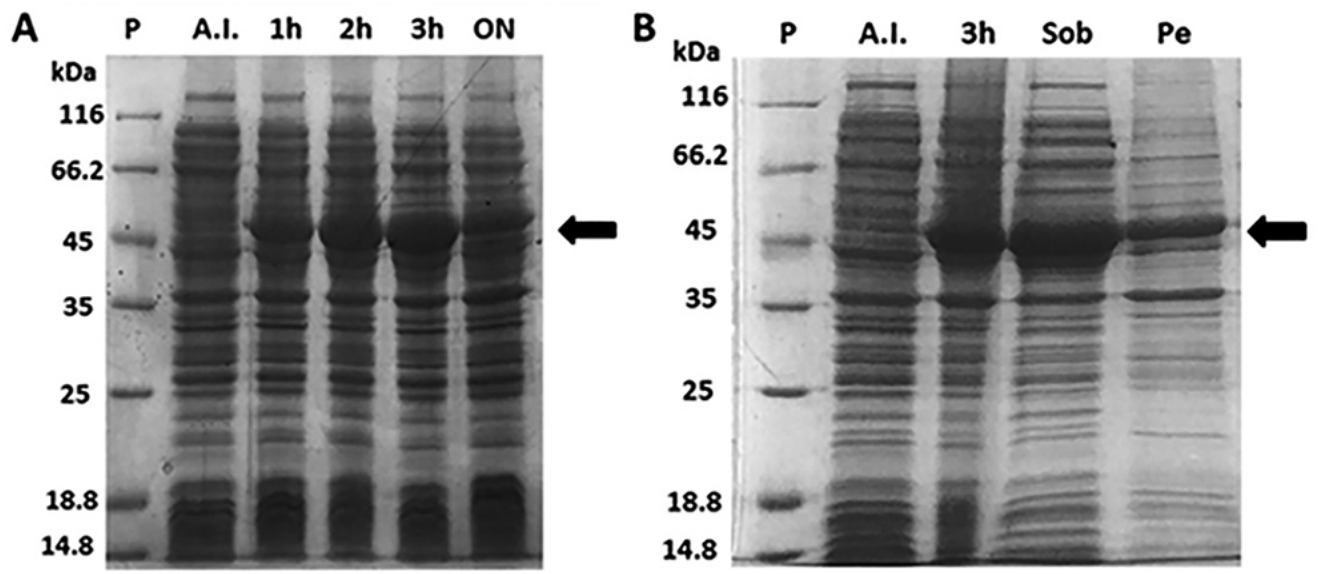

Figure 3. Heterologous expression of recombinant protein Hisx6MBP-AgCecropB and E. coli BL21 (DE3) cell lysis. (A) 12\% SDS-PAGE of Hisx6MBP$\mathrm{AgCecropB}$ expression using IPTG $(0.5 \mathrm{mM})$ to induce expression, at $28^{\circ} \mathrm{C}$. P: molecular mass standard; A.l.: aliquot before induction; $1 \mathrm{~h}, 2 \mathrm{~h}, 3 \mathrm{~h}, 4 \mathrm{~h}, \mathrm{ON}$ :

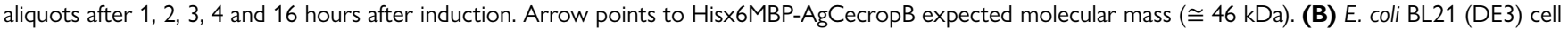
lysis after 3 hours of induction. P: molecular mass standard; A.l.: aliquot before induction; 3 h: 3 hours after induction; Sob: soluble fraction after lysis process; Pe: precipitate fraction after lysis process. Arrow points to Hisx6MBP-AgCecropB expected molecular mass (48.5 kDa).

A
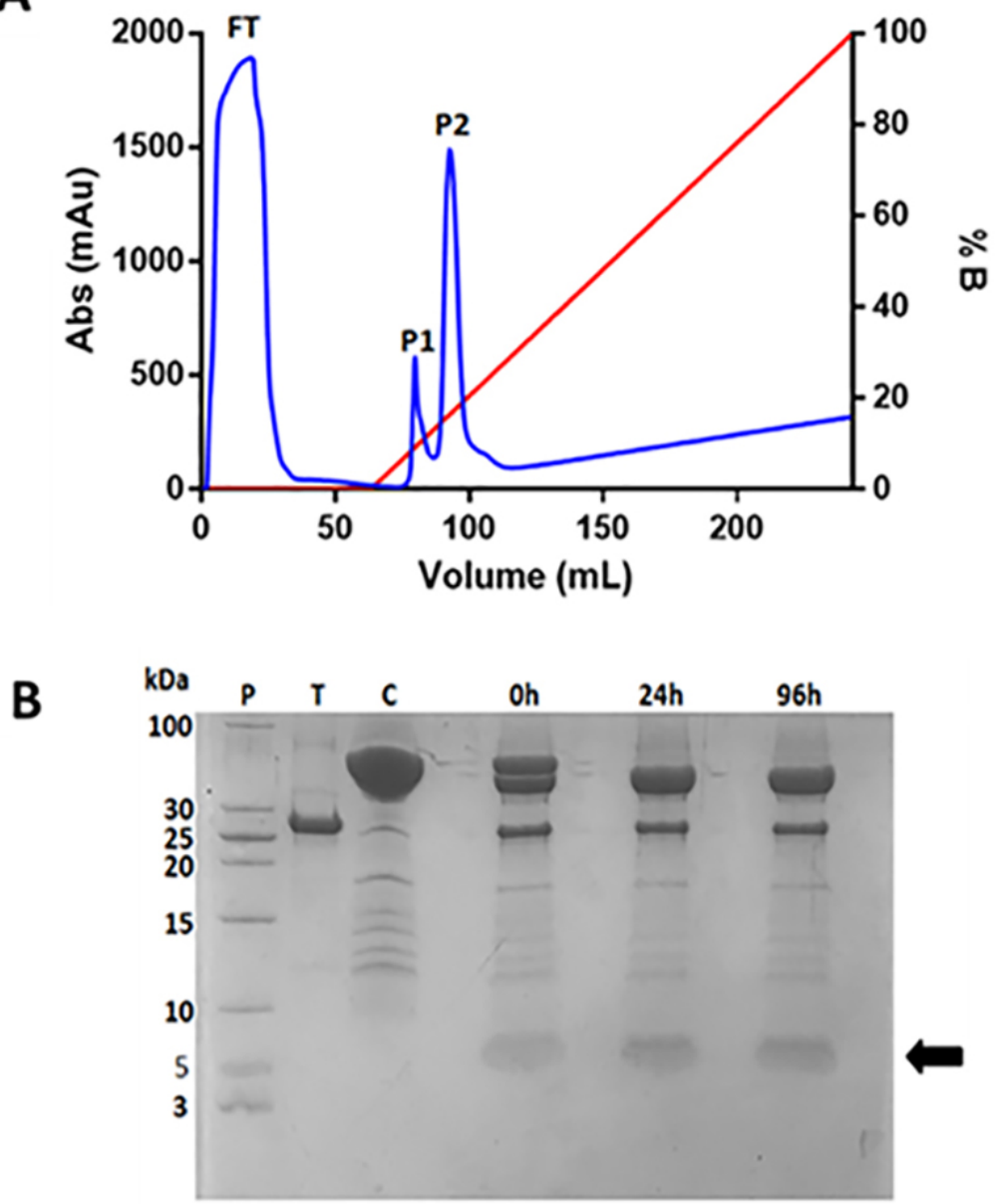

Figure 4. First purification step of recombinant protein and proteolysis assay. (A) Chromatogram of Hisx6MBP-AgCecropB purification by affinity Ni ${ }^{2+} H i s t r a p$ columns (GE healthcare). Blue line represents sample absorbance measure in $280 \mathrm{~nm}$ and red line represent elution buffer B (50 mM sodium phosphate, $0.5 \mathrm{M} \mathrm{NaCl}, 1 \mathrm{M}$ imidazole [pH 7,0]) concentration during experiment. FT: flowthrough; P1 and P2: protein peaks during chromatography elution. P2 was eluted containing Hisx6MBP-AgCecropB in $160 \mathrm{mM}$ imidazole. (B) 18\% SDS-PAGE gel of proteolysis assay using TEV endoprotease. P2 fraction was dialysate to extract imidazole and quantified by Qubit for proteolysis assay, using 5:1 proportion (mass/mass) (protein:TEV). P: molecular mass standard; T: TEV endoprotease (28 kDa); C: P2 containing Hisx6MBP-AgCecropB; Oh: aliquot withdrawal at the exact moment TEV and recombinant protein were mixed; 24h and 96h: aliquots of 24 hours and 96 hours, respectively, after cleavage. Arrow indicates recombinant peptide AgCecropB. 


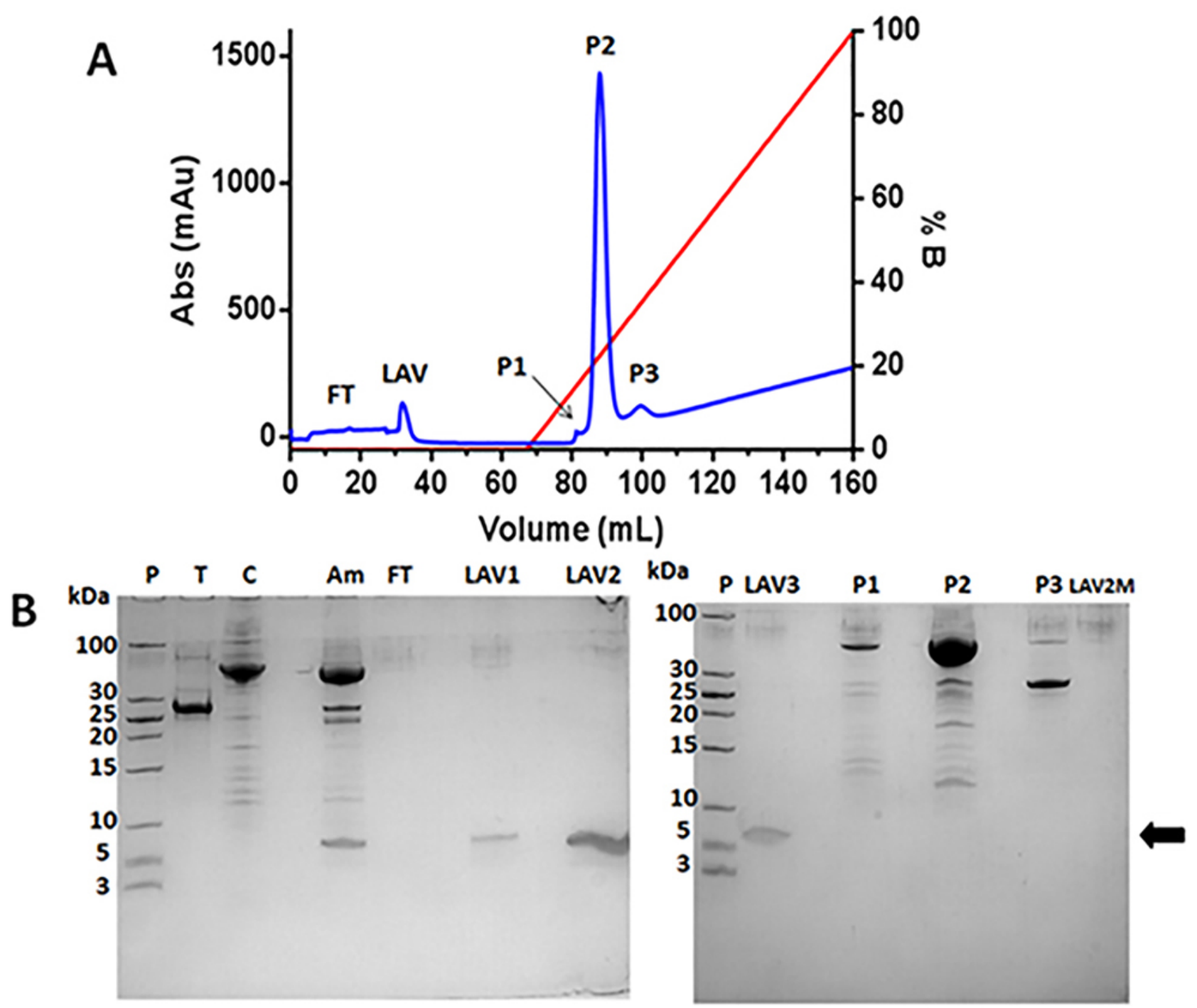

Figure 5. Second purification step to purify AgCecropB. (A) Chromatogram purification by affinity $\mathrm{Ni}^{2+} \mathrm{Histrap}$ columns (GE healthcare). Blue line represents sample absorbance measure in $280 \mathrm{~nm}$ and red line represent elution buffer $\mathrm{B}(50 \mathrm{mM}$ sodium phosphate, $0.5 \mathrm{M} \mathrm{NaCl}, 1 \mathrm{M}$ imidazole [pH 7,0]) concentration during experiment. FT: flowthrough; LAV: peak obtained during washing column buffer (50 mM sodium phosphate, 0.5 M NaCl [pH 7,0]). P1, P2, P3: peaks eluted during buffer B gradient. (B) 18\% SDS-PAGE gel with chromatography fractions. P: molecular mass standard; T: TEV endoprotease (28 kDa); C: P2 containing Hisx6MBP-AgCecropB; Am: proteolysis sample after 96 hours assay. FT: flowthrough; LAV1, LAV2, LAV3: collected fractions from LAV peak; P1, P2, P3: eluted samples during buffer B gradient; LAV2M: Histrap column sample collected after final washing (2 M imidazole). Arrow indicates recombinant peptide AgCecropB identified in LAV fractions.

expected mass of recombinant AgCecropB. Structural studies of $\mathrm{AgCecropB}$ peptide was performed using circular dichroism and tryptophan intrinsic fluorescence, to obtain information about the secondary and tertiary structure contents of the protein in the presence of a membrane mimicry. CD spectra of the peptide in the presence of two different concentrations (50 and 100 $\mathrm{mM}$ ) of SDS showed a gain of helical content indicated by the decrease of molar ellipticity value at $222 \mathrm{~nm}$ (Fig 6B). The tertiary structural features of the recombinant peptide were monitored by intrinsic fluorescence. The data showed that the spectral center mass decreased in the presence of SDS, with spectrum migration to the red, indicating structural gain (Figure 6C), which corroborates with $\mathrm{CD}$ results. It means that the tryptophan, in the presence of SDS, is less exposed to the solvent, probably because of AgCecropB peptide gained structural helical contents or due to its interaction with SDS micelles.

\section{Antimicrobial tests}

AgCecropB antimicrobial activity was tested against a grampositive (Bacillus thuringiensis) and two gram-negative (B. kururiensis and E. coli) bacteria (Figure 7). Chloramphenicol antibiotic inhibition was nearly $90 \%$ considering all three bacteria growth, as expected for this antibiotic (positive inhibition control). The data showed AgCecropB inhibited almost $50 \%$ of $B$. thuringiensis growth after 20 hours of culture growth. There was no observed effect in B. kururiensis or E. coli. 

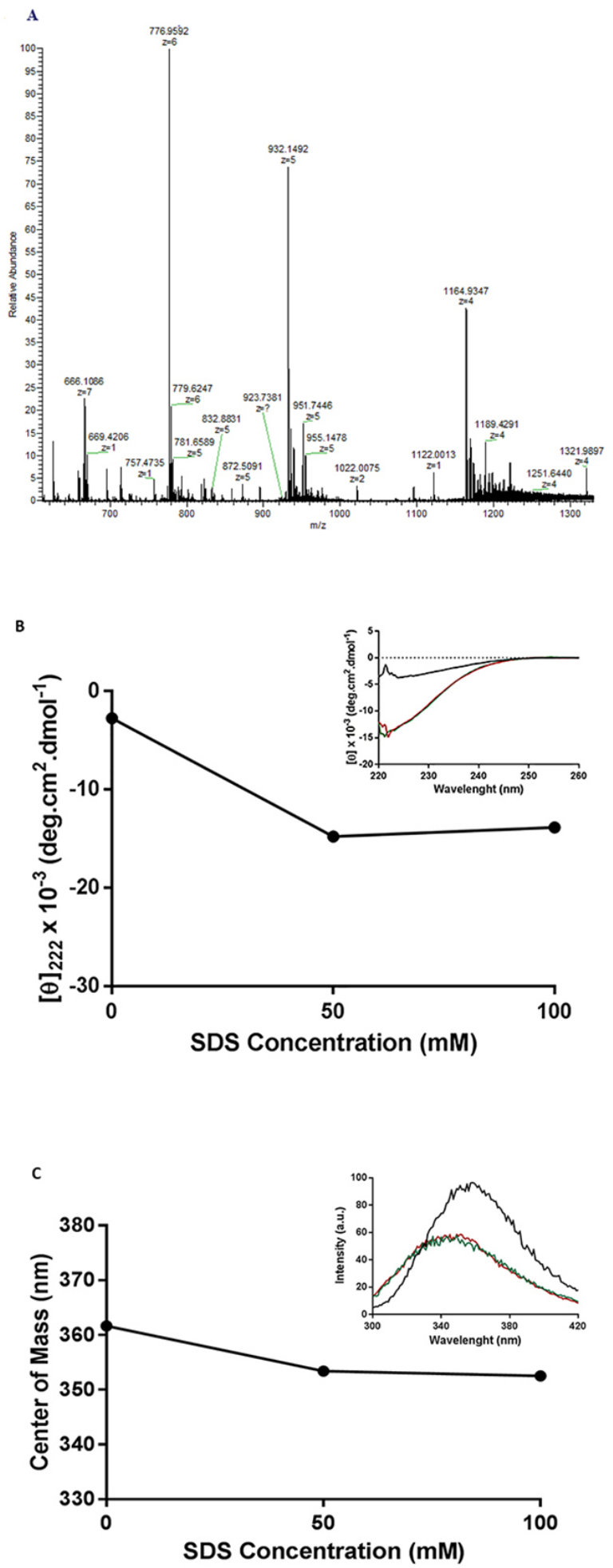

Figure 6. HRMS and secondary structure assays of AgCecropB. (A) Mass spectrum chromatogram of purified recombinant cecropin B. On the $X$ axis, the detected fragments and their charge in the spectrum are identified; the $Y$ axis shows the intensity of the fragments, based on their relative abundance. (B) Mean residue molar ellipticity at $222 \mathrm{~nm}$ of recombinant peptide $\mathrm{AgCecropB}$ in the presence of SDS. In the $X$ axis the SDS molar concentration is expressed and in the $Y$ axis is plotted the $A g C e c r o p B$ mean residue molar ellipticity value at $222 \mathrm{~nm}$. Inset: circular dichroism spectrum $(220-260 \mathrm{~nm})$. $X$ axis shows the wavelength and in the $Y$ axis the mean residue molar ellipticity. Black line: control without SDS; red line: AgCecropB in the presence of SDS $50 \mathrm{mM}$; green line: $\mathrm{AgCecropB}$ in the presence of SDS $100 \mathrm{mM}$. (C) Center of mass analysis plot at $280 \mathrm{~nm}$. In the $X$ axis the SDS molar concentration is expressed and in the $Y$ axis is plotted the uptake wavelength of $A g C e c r o p B$ center of mass. Inset: tryptophan intrinsic fluorescence assay plot measured at $280 \mathrm{~nm}$; in the $X$ axis is showed the absorption wavelength and in the $Y$ axis the fluorescence intensity. Black line: control without SDS; red line: AgCecropB in the presence of SDS 50 $\mathrm{mM}$; green line: AgCecropB in the presence of SDS $100 \mathrm{mM}$. 


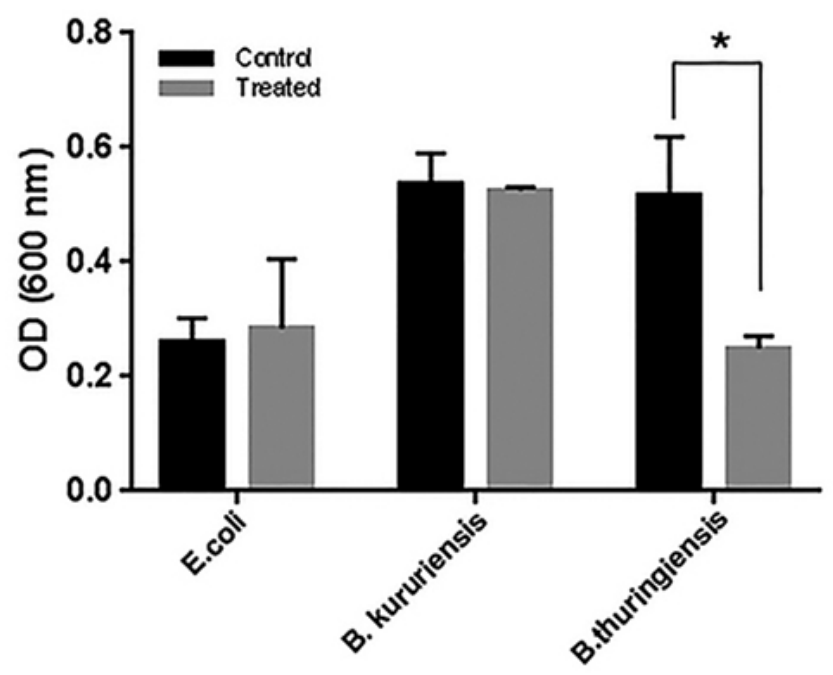

Figure 7. Effect of $A g C e c r o p B$ in the bacterial growth. E. coli, B. kururiensis and $B$. thuringiensis were exposed to $9 \mu \mathrm{M}$ of AgCecropB (grey bars) for 20 hours and OD $600 \mathrm{~nm}$ was measure. Control samples (black bars) were not exposed to recombinant peptide. Experiment was performed in quintuplicate, and statistical analysis (two-way ANOVA and Bonferroni's multiple comparisons test) was developed by using the software Graph Pad Prism 7.0 (asterisks mean these compared groups were significantly different).

\section{Discussion}

Antimicrobial peptides are important components of the humoral defense of insects, showing activity against gram-positive and gram-negative bacteria, fungi, viruses, and parasites. The action mechanism of most antimicrobial peptides is characterized by the disruption of the microorganism cell membrane [40].

Most cecropin-like peptides have one or two aromatic residues near the $\mathrm{N}$-terminal portion. Tryptophan residues at position 2 and phenylalanine at position 5 are highly conserved on mature peptide [41]. These peptides are generally composed of an amphipathic $\mathrm{N}$-terminal $\alpha$-helix and a hydrophobic C-terminal a-helix, linked by a hinge region $[42,43]$. Bioinformatics analysis of cecropin-B-like from $A$. gemmatalis revealed its amino acid sequence homology with other cecropins described in insects, showing that mostly conservative amino acids are comprehended in mature peptide sequence. It was observed by Durell et al. [44] that cecropins N-terminal helix has a net positive formal charge (amphipathic), whereas the C-terminal helix is less charged (hydrophobic), and the hinge between the helices is formed by the glycine and proline residues which are conserved in cecropins, including AgCecropB. We have also predicted tridimensional similarity with papiliocin, a cecropin from the butterfly species Papilio xuthus, and the main structural model of cecropins $[45,46]$.

Structural studies of Circular Dichroism and intrinsic fluorescence of tryptophan have been used to analyze the structural features of antimicrobial peptides [41,47,48]. Recombinant cecropin-B-like structural assays suggested an a-helix conformation when AgCecropB is in contact with SDS. This is similar to what has been previously described $[49,50]$. In an aqueous environment without the detergent, the peptide is found in a random coil structure. In this case, SDS simulates the microorganism membrane, that is negatively polarized due to the presence of the phosphate group in different membrane components. Therefore, this anionic characteristic helps in the action of antimicrobial peptides, which have a cationic charge, resulting in strong interactions. In its natural environment, the peptide only gains structure and activity when in contact with the membrane of a microorganism [51]. As showed in our data, AgcecropB only gained tertiary structure in the presence of SDS, indicating the dependence of a membrane proximity or association to this effect.

To produce the recombinant peptide, a cecropin-B-like partial sequence was cloned in a plasmid containing an MBP solubility tag, a Hisx6 tag, and a cleavage site for TEV endoprotease. Heterologous expression protocols with solubility tags are widely used in the literature [52-55]. These different tags help in the correct folding of protein, solubilization, purification, and protecting the recombinant peptides against the degradation produced by intracellular proteases [56]. MBP tag is a frequently used fusion tag to enhance molecule solubility [57] and is also capable to interact with hydrophobic amino acid residues present in unfolded proteins [58]. In that sense, cecropins have been described as unfolded peptides and the MBP tag could prevent its aggregation. Hisx6-tag is widely used for AMP purification using affinity chromatography steps [59]. MBP and Hisx6 tag were cleaved by TEV endoprotease, that recognizes the short sequence (ENLYFQ $\downarrow$ G) already inserted into the plasmid gene sequence [60]. This protocol is successful and efficient to produce a recombinant and functional peptide, as showed by our data.

Three different bacteria were chosen for antimicrobial assays. AgCecropB did not inhibit the growth of gram-negative bacteria, such as Burkholderia kururiensis and E. coli DH5a. On the other side, AgCecropB was effective against the gram-positive $B$. thuringiensis. This bacteria species is one of the most important biological control agents used against agricultural pests. It produces delta-endotoxins, known as Cry toxins, that have activity against many insects [61], including A. gemmatalis caterpillar [62]. Former studies about AMP antimicrobial activity against $B$. thuringiensis showed that AMP encoding genes from Trichoplusia ni were increased in insects which were previously exposed to these bacteria [63]. Also, cecropins, moricins and gloverins from Bombyx mori showed a high antimicrobial activity against B. thuringiensis [64]. In Spodoptera spp, the response to B. thuringiensis infection depends on several biological factors, such as the production of AMPs [65]. The knockdown of gloverin increased the susceptibility to B. thuringiensis in Spodoptera exigua, suggesting that this immune response could be related to resistance development [66]. Considering the importance 
of $B$. thuringiensis for A. gemmatalis biological control in soybean fields, it would be worthy to study a possible action of an antimicrobial peptide of this insect in the presence of the bacteria. These analyses could bring some new information about the developing of $A$. gemmatalis resistance to $B$. thuringiensis in the soybean crops.

\section{Conclusions}

A cecropin B-like peptide sequence was identified in $A$. gemmatalis midgut transcriptome and predicted a tertiary structure based on a two a-helix model. AgCecropB was cloned in pETM30-MBP plasmid and expressed using E. coli BL21 (DE3). The recombinant peptide was obtained by two steps of affinity purification and a cleavage step using TEV protease. LC-MS/ MS and secondary structure data confirmed its molecular mass and the presence of $\alpha$-helix when exposed to SDS. Antimicrobial tests suggest that AgCecropB can disrupt Bacillus thuringiensis growth, which may be a pathway activated by $B$. thuringiensis infection during its use as a biological control for this soybean pest. It would be very interesting to study the correlation between the expression of antimicrobial peptides and the emergence of resistance to Bt.

\section{Acknowledgments}

We express our gratitude to Bianca C. Neves (Department of Biochemistry, Institute of Chemistry, UFRJ) for kindly providing laboratory supplies and facilities, and to Ednildo A. Machado (Carlos Chagas Filho Institute of Biophysics, UFRJ) for providing bioinformatics data.

\section{Availability of data and materials}

All relevant data, associated protocols, and used materials are available within the manuscript file.

\section{Funding}

This work was supported by Carlos Chagas Filho Foundation for Supporting Research in the State of Rio de Janeiro (FAPERJ); Coordination for the Improvement of Higher Education Personnel (CAPES - Finance Code 001) and the National Council for Scientific and Technological Development (CNPq).

\section{Competing interests}

The authors have declared that no competing interests exist.

\section{Authors' contributions}

LFCR, JHOR, and DMPO wrote the main manuscript. LFCR and JHOR carried out most experiments. GCA and CDAB conducted structural experiments. FCSN conducted MS experiments. CL and ASP contributed to design cloning experiments. FMG contributed to sequence data and reviewed the manuscript. LVAC, RVA, CDAB, and DMPO contributed to reagents/ materials/data analysis. RVA and DMPO coordinated the study and supervised experiments. LFCR and DMPO conceptualized the study. All authors revised and approved the final manuscript.

\section{Ethics approval}

Not applicable.

\section{Consent for publication}

Not applicable.

\section{References}

1. Stork NE. How many species of insects and other terrestrial arthropods are there on earth? Annu Rev Entomol. 2017 Jan 7;63:31-45.

2. Flores-Villegas AL, Salazar-Schettino PM, Córdoba-Aguilar A, GutiérrezCabrera AE, Rojas-Wastavino GE, Bucio-Torres MI, et al. Immune defence mechanisms of triatomines against bacteria, viruses, fungi and parasites. B Entomol Res. 2015 Oct;105(5):523-32.

3. Terra WR, Ferreira C. Insect digestive enzymes: properties, compartmentalization and function. Comp Biochem Phys B. 1994 Sep;109(1):1-62.

4. Anggraeni T, Ratcliffe NA. Studies on cell-cell co-operation during phagocytosis by purified haemocyte populations of the wax moth, Galleria mellonella. J Insect Physiol. 1991 Mar;37(6):453-60.

5. Nesa J, Sadat A, Buccini DF, Kati A, Mandal AK, Franco OL. Antimicrobial peptides from Bombyx mori: a splendid immune defense response in silkworms. RSC Adv. 2020 Jan;10:512-23.

6. Yi HY, Chowdhury M, Huang YD, Yu XQ. Insect antimicrobial peptides and their applications. Appl Microbiol Biotechnol. 2014 Jul;98(13):5807-22.

7. Lee KH, Hong SY, Oh JE. Synthesis and structure-function study about tenecin 1, an antibacterial protein from larvae of Tenebrio molitor. FEBS Lett. 1998 Nov 13;439(1-2):41-5.

8. Aerts AM, François IEJA, Cammue BPA, Thevissen K. The mode of antifungal action of plant, insect and human defensins. Cell Mol Life Sci. 2008 Jul;65(13):2069-79.

9. Sun HX, Chen LQ, Zhang J, Chen FY. Anti-tumor and immunomodulatory activity of peptide fraction from the larvae of Musca domestica. J Ethnopharmacol. 2014 May;153(3):831-9.

10. An S, Dong S, Wang Q, Li S, Gilbert LI, Stanley D, et al. Insect neuropeptide bursicon homodimers induce innate immune and stress genes during molting by activating the NF- $\mathrm{kB}$ transcription factor relish. PLoS One. 2012 Mar 28;7(3):e34510.

11. Zuo YH, Chen ME. Differential gene expression in male and female fat body in the original fruit fly, Bactrocera dorsalis. Arch Insect Biochem Physiol. 2014 Jan;85(1):48-59.

12. Boulanger N, Bulet $P$, Lowenberger $C$. Antimicrobial peptides in the interactions between insects and flagellate parasites. Trends Parasitol. 2006 Jun;22(6):262-8

13. Bulet P, Hetru C, Dimarcq JL, Hoffmann D. Antimicrobial peptides in insects; structure and function. Dev Comp Immunol. 1999 JunJul;23(4-5):329-44.

14. Hultmark D, Steiner $H$, Rasmuson T, Boman HG. Purification and properties of three inducible bactericidal proteins from hemolymph of immunized pupae of Hyalophora cecropia. Eur J Biochem. 1980 May;106(1): 7-16.

15. Zhao L, Alto BW, Jiang Y, Yu F, Zhang Y. Transcriptomic analysis of Aedes aegypti innate immune system in response to ingestion of Chikungunya virus Int J Mol Sci. 2019 Jun 27;20(13):3133. 
16. Liu FH, Lin XL, Kang ZW, Tian HG, Liu TX. Isolation and characterization of Pseudomonas cedrina infecting Plutella xylostella (Lepidoptera: Plutellidae). Arch Insect Biochem Physiol. 2019 Jul 10:102(3):1-13.

17. Vertyporokh L, Wojda I. Immune response of Galleria mellonella after injection with non-lethal and lethal dosages of Candida albicans. J Invertebr Pathol. 2020 Feb;170:1-9.

18. Wang L, Li Z, Du C, Chen W, Pang Y. Characterization and expression of a cecropin-like gene from Helicoverpa armigera. Comp Biochem Physiol B Biochem Mol Biol. 2007 Dec;148(4):417-25.

19. Brady D, Grapputo A, Romoli O, Sandrelli F. Insect cecropins, antimicrobial peptides with potential therapeutic applications. Int J Mol Sci. 2019 Nov 22;20(23):5862.

20. Wang S, Zeng X, Yang Q, Qiao S. Antimicrobial peptides as potential alternatives to antibiotics in food animal industry. Int J Mol Sci. 2016 May 3;17(5):603.

21. Wang M, Lin J, Sun Q, Zheng K, Ma Y, Wang J. Design, expression, and characterization of a novel cecropin A-derived peptide with high antibacterial activity. Appl Microbiol Biotechnol. 2019 Jan 4;103:1765-75.

22. Shrestha A, Duwadi D, Jukosky J, Fiering SN. Cecropin-like antimicrobial peptide protects mice from lethal E.coli infection. PLoS One. 2019;14(7):e0220344.

23. Kalsy M, Tonk M, Hardt M, Dobrindt U, Zdybicka-Barabas A, Cytrynska M, et al. The insect antimicrobial peptide cecropin A disrupts uropathogenic Escherichia coli biofilms. NPJ Biofilms Microbiones. 2020 Feb 12;6(6):1-8.

24. Lü D, Geng T, Hou C, Qin G, Gao K, Guo X. Expression profiling of Bombyx mori gloverin2 gene and its synergistic antifungal effect with cecropin $A$ against Beauveria bassiana. Gene. 2017 Feb 5;600:55-63.

25. Hoffman-Campo CB, Moscardi F, Corrêa-Ferreira BS, Oliveira LJ, SosaGómez DR, Panizzi AR, et al. Pragas da soja no Brasil e seu manejo integrado. Embrapa-CNPSo. 2000;30:1-70.

26. Ford BJ, Strayer JR, Reid J, Godfrey GL. The literature of arthropods associated with soybean, a bibliography of the velvetbean caterpillar Anticarsia gemmatalis Hübner (Lepidoptera: Noctuidae). Biol Notes.1975 Feb;92:1-24

27. Levy SM, Falleiros AMF, Moscardi F, Gregório EA. The role of peritrophic membrane in the resistance of Anticarsia gemmatalis larvae (Lepidoptera: Noctuidae) during the infection by its nucleopolyhedrovirus (AgMNPV). Arthropod Struct Dev. 2011 Sep;40(5):429-34.

28. Mushtaq R, Behle R, Liu R, Niu L, Song P, Shakoori AR, et al. Activity of Bacillus thuringiensis Cry1le2, Cry2Ac7, Vip3Aa11 and Cry7Ab3 proteins against Anticarsia gemmatalis, Chrysodeixis includens and Ceratoma trifurcata. J Invertebr Pathol. 2017 Nov;150:70-2.

29. Silva G, Ramos LFC, Seckler, HS, Gomes FM, Cortines JR, Ramos I, et al. Biochemical characterization of digestive membrane-associated alkaline phosphatase from the velvet bean caterpillar Anticarsia gemmatalis. Arch Insect Biochem Physiol. 2019 Jul;102(1):1-14.

30. Heringa J. Two strategies for sequence comparison: profile-preprocessed and secondary structure-induced multiple alignment. Comput Chem. 1999 Jun 15;23(3-4):341-64.

31. Petersen TN, Brunak S, Heijne G, Nielsen H. SignalP 4.0: discriminating signal peptides from transmembrane regions. Nat Methods. $2011 \mathrm{Sep}$ 29;8:785-6.

32. Chomczynski P, Sacchi N. Single-step method of RNA isolation by acid guanidinium thiocyanate-phenol-chloroform extraction. Anal Biochem. 1987 Apr;162(1):156-9.

33. Lixa C, Marques AF, Cortines JR, Neves BC, Oliveira DMP, Anobom CD. Refolding, purification, and preliminary structural characterization of the DNA-binding domain of the quorum sensing receptor RhIR from Pseudomonas aeruginosa. Protein Expres Purif. 2016 May;121:31-40.

34. Peti W, Page R. Strategies to maximize heterologous protein expression in Escherichia coli with minimal cost. Protein Expr Purif. 2007 Jan;51(1):1-10.

35. Laemmli UK. Cleavage of structural proteins during assembly of head of bacteriophage T4. Nature. 1970 Aug 15;227(5259):680-5.

36. Syrovy L, Hodny Z. Staining and quantification of proteins separated by polyacrylamide gel electrophoresis. J Chromatogr. 1991 Sep 13;569 $(1-2): 175-96$.
37. Cunha DAB, Bartkevihi L, Robert JM, Cipolatti EP, Ferreira ATS, Oliveira DMP, et al. Structural differences of commercial and recombinant lipase B from Candida antarctica: An important implication on enzymes thermostability. Int J Biol Macromol. 2019 Nov 1;140:761-70.

38. Kim SR, Hong MY, Park SW, Choi KH, Yun EY, Goo TW, et al. Characterization and cDNA cloning of a cecropin-like antimicrobial peptide, papiliocin, from the swallowtail butterfly, Papilio xuthus. Mol Cells. 2010 Apr;29(4):419-23.

39. Hanahan D, Jessee J, Bloom FR. Plasmid transformation of Escherichia coli and other bacteria. Methods Enzymol. 1991;204(4):63-113.

40. Zasloff M. Antimicrobial peptides in health and disease. N Engl J Med. 2002 Oct 10;347(15):1199-200.

41. Lee $E$, Kim JK, Jeon D, Jeong KW, Shin A, Kim Y. Functional roles of aromatic residues and helices of papiliocin in its antimicrobial and antiinflammatory activities. Sci Rep. 2015 Jul 9;5:12048.

42. Morishima I, Suginaka S, Ueno T, Hirano H. Isolation and structure of cecropins, inducible antibacterial peptides, from the silkworm, Bombyx mori. Comp Biochem Physiol B. 1990;95(3):551-4.

43. Liang Y, Wang JX, Zhao XF, Du XJ, Xue JF. Molecular cloning and characterization of cecropin from the housefly (Musca domestica), and its expression in Escherichia coli. Dev Comp Immunol. 2006;30(3):249-57.

44. Durell SR, Raghunathan G, Guy HR. Modeling the ion channel structure of cecropin. Biophys J. 1992 Dec;63(6):1623-31.

45. Marassi FM, Opella SJ, Juvvadi P, Merrifield RB. Orientation of cecropinA helices in phospholipid bilayers determined by solid-state NMR spectroscopy. Biophys J. 1999 Dec;77(6):3152-5.

46. Saito A, Ueda K, Imamura M, Atsumi S, Tabunoki H, Miura N. Purification and cDNA cloning of a cecropin from the longicorn beetle, Acalolepta luxuriosa. Comp Biochem Physiol B Biochem Mol Biol. 2005 Nov;142(3): 317-23.

47. Fang SL, Wang L, Fang Q, Chen C, Zhao XS, Qian C, et al. Characterization and functional study of a Cecropin-like peptide from the Chinese oak silkworm, Antheraea pernyi. Arch Insect Biochem Physiol. 2016 Jan;94(1): $1-13$.

48. Kaushal A, Gupta K, Hoek MVL. Characterization of Cimex lectularius (bedbug) defensin peptide and its antimicrobial activity against human skin microflora. Biochem Biophys Res Commun. 2016 Feb 19;470(4):955-60.

49. Shen X, Ye G, Cheng X, Yu C, Yao H, Hu C. Novel antimicrobial peptides identified from an endoparasitic wasp cDNA library. J Pept Sci. 2010 Jan;16(1):58-64.

50. WU J, Mu L, Zhuang L, Han Y, Liu T, Li J, et al. A cecropin-like antimicrobial peptide with anti-inflammatory activity from the black fly salivar glands. Parasit Vectors. 2015 Oct 24;8:561.

51. Zdybicka-Barabas A, Stączek S, Pawlikowska-Pawlęga B, Mak P, Luchowski R, Skrzypiec K, et al. Studies on the interactions of neutral Galleria mellonella cecropin D with living bacterial cells. Amino Acids. 2019 Feb;51(2):175-91.

52. Jin F, Sun Q, Xu X, Li L, Gao G, Xu Y, et al. cDNA cloning and characterization of the antibacterial peptide cecropin 1 from the diamondback moth, Plutella xylostella L. Protein Expr Purif. 2012 Oct;85(2):230-8.

53. Al-Souhail Q, Hiromasa Y, Rahnamaeian M, Giraldo MC, Takahashi $D$, Valent $B$, et al. Characterization and regulation of expression of an antifungal peptide from hemolymph of an insect, Manduca sexta. Dev Comp Immunol. 2016 Aug;61:258-68.

54. Xu XX, Zhang YQ, Freed S, Yu J, Gao YF, Wang S, et al. An anionic defensin from Plutella xylostella with potential activity against Bacillus thuringiensis. Bull Entomol Res. 2016 Dec;106(6):790-800.

55. Hayat SMG, Farahani N, Golichenari B, Sahebkar A. Recombinant protein expression in Escherichia coli (E.coli): what we need to know. Curr Pharm Des. 2018;24(6):718-25.

56. Ki MR, Pack SP. Fusion tags to enhance heterologous protein expression. Appl Microbiol Biotechnol. 2020 Mar;104(6):2411-25.

57. Needle D, Waugh DS. Rescuing aggregation-prone proteins in Escherichia coli with a dual His (6)-MBP tag. Methods Mol Biol. 2014;1177:81-94.

58. Li Y. Recombinant production of antimicrobial peptides in Escherichia coli: a review. Protein Expr Purif. 2011 Dec;80(2):260-7. 
59. Owczarek B, Gerszberg A, Hnatuszko-Konka K. A brief reminder of systems of production and chromatography-based recovery of recombinant protein biopharmaceuticals. Biomed Res Int. 2019 Jan8;2019:4216060.

60. Kapust RB, Tözsér J, Fox JD, Anderson DE, Cherry S, Copeland TD, et al. Tobacco etch virus protease: mechanism of autolysis and rational design of stable mutants with wild-type catalytic proficiency. Protein Eng. 2001 Dec;14(12):993-1000.

61. Torres-Quintero MC, Gómez I, Pacheco S, Sánchez J, Flores H, Osuna $\mathrm{J}$, et al. Engineering Bacillus thuringiensis Cyt1Aa toxin specificity from dipteran to lepidopteran toxicity. Sci Rep. 2018 Mar 21;8(4989):1-12.

62. Fiuza LM, Knaak N, Silva RFP, Henriques JAP. Receptors and lethal effect of Bacillus thuringiensis insecticidal crystal proteins to the Anticarsia gemmatalis (Lepidoptera, Noctuidae). ISRN Microbiol. 2013;2013:940284.
63. Tamez-Guerra P, Valadez-Lira JA, Alcocer-González JM, Oppert B, GomezFlores R, Tamez-Guerra R, et al. Detection of genes encoding antimicrobial peptides in Mexican strains of Trichoplusia ni (Hübner) exposed to Bacillus thuringiensis. J Invertebr Pathol. 2008 Jun;98(2):218-27.

64. Nesa J, Sadat A, Buccini DF, Kati A, Mandal AK, Franco OL. Antimicrobial peptides from Bombyx mori: a splendid immune defense response in silkworms. RSC Adv. 2020 Jan;10:512-23.

65. Herrero S, Bel Y, Hernández M, Ferré J. Susceptibility, mechanisms of response and resistance to Bacillus thuringiensis toxins in Spodoptera spp. Curr Opin Insect Sci. 2016 Jun;15:89-96.

66. Hwang J, Kim Y. RNA interference of an antimicrobial peptide, gloverin, of the beet armyworm, Spodoptera exigua, enhances susceptibility to Bacillus thuringiensis. J Invertebr Pathol. 2011 Nov;108(3):194-200. 